\title{
The Problems of Implementing CLIL in Italy
}

\author{
Graziano Serragiotto \\ Ca' Foscari University, Venice, Italy \\ E-mail: serragiotto@unive.it
}

Received: Sep. 10, 2017 Accepted: Sep. 20, 2017 Published: September 21, 2017

doi:10.5296/ijl.v9i5.11829ＵRL: https://doi.org/10.5296/ijl.v9i5.11829

\begin{abstract}
This article highlights the problems involved in implementing CLIL methodology. A general framework is initially offered as to how CLIL is applied in Italy institutionally. Then, thanks to the underwriter's experience as a CLIL educator and researcher, other issues will be taken into consideration, such as contextualization, teachers, and balancing between language and content in order to realize a CLIL process in line with the language and content objectives established by its design. The purpose of this study is therefore to elaborate suitable practices that result being a helpful tool to teachers working in a CLIL environment.
\end{abstract}

Keywords: Plurilingualism, CLIL, Double learning process 


\section{MIN Macrothink}

\section{CLIL within the Educational System}

According to Dalton-Puffer (2011), CLIL concerns all those scholastic and business organizations that want to help give a formal, educational, linguistic, specialistic and professional development to the aspirations of those individuals who are willing to obtain a multilingual profile in order to have better chances in finding a job and being successful in the working environment (Johnson \& Swain, 1994).

CLIL therefore represents one of the most suitable methodologies to favor a double learning process, of language and specific knowledge, catering both to multilingual-inspired contexts (Marsh \& Wolf, 2007) and bilingual educational programs.

This concept underscores the system of values and objectives characterizing CLIL teaching: a specific subject-matter is favored by the use of a foreign language and the acquisition of a specific subject-matter competence is accompanied by an improvement in the field of language.

These characteristics lead to teaching processes focused on the need to:

a. integrate language input with the subject-matter so that both become complementary in realizing an incisive teaching process capable of stimulating the development of metacognitive abilities and cross-curricular competences (Serragiotto, 2011); and

b. convey contents effectively, where what becomes fundamental is not formal correctness, but, as stated by Graaff et al. (2007), the fact that the input, the content being conveyed, is both factual and reliable and at the same time understandable.

In this perspective, Dalton-Puffer (2011) regards language and subject-matter as two faces of the same coin, being that one legitimates the use and function of the other.

In their studies, O’Malley and Chamot (1990) point out the metalinguistic and metacognitive value of CLIL in that it activates a process that stimulates the microlinguistic dynamics faced in class and thus supporting a new attitude and communicational behavior based on the true skill of using a foreign language to deepen non-linguistic content.

Therefore, CLIL is meant to be used in an educational system that, in the view of Lasagabaster and Serra (2009), defines culture as a multidimensional structure that combines a series of fundamental values meant to prepare a certain social group to face the challenges of a global environment (Li, 2002).

\section{CLIL in Italy}

This paragraph will firstly consider the political background that has led to Italy's interest in introducing CLIL into its school curricula and, secondly, the different teaching implications implied in adopting CLIL that regard it as a methodology capable of improving the educational and professional training system. 


\subsection{The Spreading of CLIL in Italy}

The studies of Coonan (2007, 2008) and thereafter Coyle et al. (2010) have highlighted the orientation and commitment undertaken programmatically by the European Council since the early ' 90 s to spread the acquisition of foreign languages, leading therefore to the adoption of CLIL in programmatic protocols within many European institutions including Italy. The European Union protocol (2008) states:

"The European Union actively encourages its citizens to learn other European languages, both for reasons of professional and personal mobility within its single market, and as a force for cross-cultural contacts and mutual understanding [...] The ability to understand and communicate in more than one language [...] is a desirable life-skill for all European citizens. Learning and speaking other languages [...] improves cognitive skills and strengthens learners' mother tongue skills; it enables us to take advantage of the freedom to work or study in another Member State.” (A Guide to Languages in the European Union, 2008)

The experiences of CLIL carried out in Canada described by Swain and Lapkin (1982) have been useful to the European scientific community as they have helped identify some of the most crucial aspects of introducing CLIL throughout Europe. In the report by Eurydice Network (2008), the spreading of CLIL is based on the importance of achieving a far-reaching language policy initiating educational projects leading to the acquisition of plurilinguistic competences of the European citizen (Eurydice, 2012). According to Escobar Urmeneta (2010), such result can be obtained on condition that the teaching community reflects upon, and scientifically investigates, the size and quality of CLIL in Europe, guaranteeing to all teachers a proper scientific preparation about methodological terminology, teaching methods and didactic tools to be used in order to face the complexity of the latest educational challenges.

It is in this sensibility that the strategic framework for the adoption of CLIL in Italy started breaking ground with in mind the purpose of producing an improvement in the acquisition of foreign languages (Lucietto, 2009).

According to studies by De Meo (2015) and Cinganotto (2016), the curricular weight that CLIL has acquired within scholastic and university planning in Italy shows not only what kind of importance legislators have given to vehicular teaching, but also how it is held in high opinion by many educational contexts that regard CLIL as an added value to the acquisition of a foreign language.

The Italian scenario in recent years has been enriched by numerous experiences in CLIL (Coonan, 2005, 2007, 2008, 2011, 2012; Ricci Garotti, 2007; Sisti, 2012; Bosisio, 2015) regarded as a model for language education, while at the same time developing its innovative charge in establishing a different degree of proficiency and configuring a more solid level of learning. The curricular projects of many scholastic institutions, in fact, feature innovative traits because of the several types of teaching contexts and the quality of the issues raised in class, therefore guaranteeing to students more authenticity to their time and efforts spent in class and more opportunities for an exchange of knowledge in a foreign language. 
In Italy, therefore, what has taken place is a great cultural change as to how foreign languages are taught as the measures put in place are aimed at producing methodological guidelines for the realization of CLIL so that the experience in class responds to a teaching model of reference without resorting to improvisation when dealing with language-content learning (Ball et al., 2015).

\subsection{The Rules and Regulations that Govern the Introduction of CLIL in Italian Schools}

In Cinganotto (2016), the vehicular experience is set within a standardized framework: the official, institutional CLIL, made effective with Presidential Decrees for High School Reform $\mathrm{n}^{\circ} 87-89 / 2010$, is a reduced version of a proper CLIL because of economic reasons that limit the effectiveness of such methodology. According to these decrees, the teaching of non-linguistic subject-matters in a foreign language is introduced into the senior year, grade 13, of Lycées and Technical Schools and into the last three years, grades 11-13, of the Linguistic Lycée. A subject-matter is therefore completely taught in a foreign language and this is carried out by the subject teacher who, in order to activate and develop a CLIL stream in class, needs to have a certified language competence equal to a C1 level of the European Framework. Transitionally, a variation has been introduced allowing to carry out in the foreign language only 50\% of the subject-matter. The Italian school reform called "La Buona Scuola” ("The Good School”) issued in 2015 through Bill n 107, attempts to spread the vehicular methodology throughout several sectors of the educational system, especially in the bilingual German-Italian schools of the Autonomous Province of Trento. According to this law, for school years 2015-2016 and 2016-2017, the Directorate General for School Curricula of the Italian Ministry of Education commits to financing CLIL projects throughout every scholastic level in order to innovate teaching methodologies and create learning environments that result being more attractive and more laboratory-oriented. Within the framework of the "Buona Scuola” reform, the Ministry of Education, the MIUR, approved in October 2016 the National Teacher Training Plan that establishes the priority of increasing CLIL training and refreshment courses for teachers so that they may be able to devise more effective strategies and solutions to acquire simultaneously language and content within CLIL. This has in fact allowed the vehicular methodology to better spread across those territorial contexts that for historical reasons have always distinguished themselves for their inhabitants’ plurilingualism, as in the case of Trentino, Aosta Valley and Friuli-Venezia Giulia. However, in all Italian regions from north to south, the Ministry pays great attention to promoting CLIL methodology at all levels of education, as shown by the recent Ministerial Decree $n^{\circ}$ 663/2016 and Departmental Decree $n^{\circ}$ 1433/2016 which allocate important resources to vehicular projects within primary and middle schools across several regions of southern Italy.

\section{The Problems Involved in CLIL}

In the latest literature on vehicular teaching in Italy, Lucietto (2009), Coonan (2011), Sisti (2012) and Bosisio (2015) point out two different forms of CLIL: a "bottom-up" type, carried out by language and subject-matter teachers working together out of their own initiative and relying on their own expertise and potential. This form of CLIL is spontaneous, non-institutionalized, and stems from experimentation within several schools from primary 
and middle schools up to high schools, and has been thereafter successfully continued over the years by teachers who have upgraded their training through specific courses and the vast body of literature by now readily available, with their efforts resulting in numerous remarkable CLIL experiences nationwide.

The second type of CLIL is institutionalized being that it stems from ministerial projects featuring the vehicular use of a foreign language. This typology of CLIL highlights the importance of a policy in favour of plurilingualism on behalf of the Ministry MIUR incentivizing of activation of CLIL streams according to projects, both curricular and extracurricular, compliant as much as possible with the conditions that the school works within.

In the examples of CLIL experimentation reported by the authors mentioned above, what emerges is a series of issues, both theoretical and methodological, as the foreign language to be learnt must vehiculate one or more subject-matters of the curriculum, seemingly increasing the divide between the teaching of the language and its use in communicating and vehiculating micro- and macro-contents of the subject-matter.

In line of principle, the observations by Bruton (2011) as to the potential that CLIL methodology offers are completely shared and appreciated, yet at the same time, it must be made clear that not using this methodology according to standardized and proper criteria generates problems in each and every phase of its implementation.

\subsection{Theoretical Problems Involving CLIL}

CLIL methodology is often confused with microlanguage, or a language for special purposes, and this leads to misunderstandings in the operative realization of such methodology. The focus of interest in teaching a microlanguage is the language itself, not the content; it is the foreign-language teacher in person who is responsible for this and usually the content dealt with is already known to the students; actually, in many cases, students are even more competent in this than the teacher. Conversely, in the case of CLIL, the focus of interest is primarily on the contents that are not already known to the students. It goes without saying that by using the foreign language as an operational tool, students simultaneously better acquire that language.

The following chart summarizes the main differences between CLIL and microlanguage.

Table 1. Distinction between CLIL methodology and microlanguages.

\begin{tabular}{|c|c|}
\hline CLIL & MICROLANGUAGE \\
\hline \multicolumn{2}{|l|}{ FOCUS } \\
\hline $\begin{array}{l}\text { primarily on the content; the language is } \\
\text { reinforced }\end{array}$ & $\begin{array}{l}\text { primarily on the language meant as a } \\
\text { variety of a language in continuous } \\
\text { evolution used by the specialists of a } \\
\text { certain scientific or professional field }\end{array}$ \\
\hline \multicolumn{2}{|l|}{ PROTAGONISTS } \\
\hline -students; & -students: specialists of a certain scientific \\
\hline
\end{tabular}


-teachers: it could be a teacher alone in case he or she has both subject-matter and language competences; or it could be two teachers working together, the foreign-language teacher who acquires the concepts of the microlanguage, and the subject-matter teacher who acquires the methodology of teaching L2; in some cases both teachers might be co-present in class or professional sector who use a microlanguage, and learners who are acquiring that specific microlanguage; -teachers: it could a teacher alone, a professional who has the necessary competence both in the scientific-specialistic sector and in the microlanguage field; there could also be a collaboration between the teacher who does not know the microlanguage but knows the teaching techniques to deliver it, and the subject-matter expert

\section{RELATIONSHIP AMONG THE PROTAGONISTS}

-collaboration between the teachers collaboration between teacher or teachers throughout all stages, from design and and students

implementation up to the evaluation of the CLIL project;

-collaboration between students and teachers

\section{OBJECTIVES}

-plurilingualism;

-acquire professional contents;

-acquire subject-matter or topics of great interest to students;

-strengthen one's own ethnic language;

-develop Cognitive Academic Language

Proficiency (CALP) in the L2;

-develop methodological and relational

competences in all subject-matters

\section{DESIGN}

The teacher or teachers involved must:

-choose the L2;

-choose the teaching materials from among those characterizing the students' course of studies and considering their competence in the vehicular language;

-collaborate to select the core items of the subject-matter;

-establish the objectives of the course;

-allow for possible changes in the design to improve acquisition;

-establish a conjunct work-plan;

-foresee possible difficulties in the process

MATERIALS -linguistic;

-extralinguistic;

-favor the acquisition of communicational and metacognitive competences in the microlanguage;

-reach an established standard of professional knowhow
The teacher or teachers involved must: -analyze the needs of the students and also of the teacher not familiar with the microlanguage in order to select the most suitable language contents to be negotiated with the specialist students;

-identify the linguistic, extralinguistic and teaching objectives and the contents of the course;

-subdivide the course planning into self-sufficient modules 
-authentic (both printed and electronic) to be engineered into teaching materials in order to make the input understandable; -school textbooks from the country of the L2 are meant for might be very different from the context of the CLIL and also because those materials are written for native speakers (prefiguring a true language obstacle);

-the use of extralinguistic reference materials; -the use of extra in-depth and complementary reference materials

\section{ACTIVITIES \& EXERCISES}

There are different ways of teaching:

-lecture, lasting some minutes at a time, better if inductive than deductive;

-cooperative learning;

-role play, matching exercises and others that allow to autonomously produce content and reasoning in the vehicular language;

-task-based methodology;

-it is necessary to create the conditions for authentic experiences so that the language is used in a truly communicative context;

-activities that allow to see the input from different perspectives by using techniques catering to different learning styles -selected and catalogued by using a checklist; are not recommendable as the curricula they

-authentic or verisimilar, presenting situations and textual genres conceived in the area of the microlanguage being studied;

-graded according to the level of difficulty and suitable to the professional needs of the students;

-subdivided into self-sufficient blocks built around a clear topic and easily linkable to each other;

-the use of extra in-depth reference materials

The didactic techniques greatly differ according to the different psychological and social relationships among the people within the class context (for example, a business in-house course with participants from different levels of the company's organization; or a university or high school context):

-text analysis (epistemological microlanguages)

-metacognitive activities;

-activities diversified according to whether the object of study is epistemological or relational microlanguages

TESTING

-its message must be supported so that the meaning is clear and understandable;

-it concludes each module; -it belongs to the operational type

-it must gauge both the language and the content by using a grid and scores purposely designed for the two fields;

-it must respect the epistemology of the subject-matter;

-it must reflect the activities carried out in class

EVALUATION

Evaluation focuses on:

Evaluation focuses on:

-both the content and language; -the understanding, both extensive and 
-the lesson, teaching unit or module; -the product and its process by using a portfolio with anecdotal and observational files;

-the student through self-evaluation intensive, of the message conveyed by the texts;

-the ability to produce a text;

-the ability to detect and appreciate the particular stylistic and morphosyntactic features of the texts in the microlanguage. Evaluation here is instrumental, meaning the student must show that he or she has reached the specific level of knowledge required by his or her professional profile (therefore resulting in either a pass or a fail).

This distinction points out how the two entities are in fact different and should not be mistaken. Operationally, CLIL entails exercises, activities and tasks connected to the subject-matter content and the language serves the needs of this content, therefore the typically traditional exercises used to practice a language as an end in itself are totally absent. Because of the fact that the contents being delivered are unknown to the students, the strategies to make these contents understandable in class become extremely crucial. This is the fundamental aspect of CLIL that calls upon the teaching competences of the CLIL teacher.

\subsection{Linguistic Problems for Teachers and Students within CLIL}

Within this paragraph are discussed the linguistic problems of the agents involved in a CLIL detected both by research projects carried out in Italy (Coonan, 2007, 2011; Ricci Garotti, 2007; Serragiotto, 2011) and by training and research activity accomplished by the underwriter in Italian schools for the ministerial certification for CLIL, the CeCLIL.

Problematic CLIL settings are linked to the linguistic knowledge of the subject-matter teachers who are required by the 2015 Decree to have a language-proficiency level equal to a C1 of the Common European Framework of Reference for Languages. What has often been reported is that the subject-matter teachers cannot count on having that level of language competence required to deliver the contents foreseen by their discipline in the foreign language of choice. This implies that such teachers are not fluent in the language and are not capable of explaining or giving in-depth and targeted information on the topic being dealt with; they have in fact true difficulties in handling communicative situations, ending up in many cases in a situation for which their students may have a level of language proficiency superior to their own. It is clear therefore that the linguistic standard offered by the teachers to their students may result inadequate as, on the one hand, it represents an impediment to the proper understanding of the content and, on the other, it misrepresents the linguistic model that higher levels of education aim at that requires that the language be fluent and articulated (Sylvén, 2013). 


\section{Mll Macrothink}

International Journal of Linguistics

ISSN 1948-5425

2017, Vol. 9, No. 5

This has determined the need for the Ministry MIUR to activate an extensive training plan allowing subject-matter teachers to reach the level of language competence needed for CLIL: at least four years are scheduled for those teachers with a B1 level of linguistic-communicative competences, and two for those with a B2 level.

As to the language competence threshold, it is believed that even a B2 level could in the end be enough; what is in fact missing are language courses targeting the needs of the subject-matter disciplines and class management in the L2. A standard language course not gauged on the specific linguistic needs of a subject-matter cannot give the fluency and confidence that teachers need to handle content and moments of interaction in class.

As to student language competence, first of all it is necessary to take into account that no class is linguistically homogeneous and this entails that the teacher needs to come up with suitable, diversified activities to involve the entire class. What is therefore crucial is an initial screening of the language competences within the class. Another factor that needs to be kept in mind is that a foreign language is used to teach another subject that features its own didactic objectives that do not overlap with those of the vehicular language. This means that the focus of interest shifts from form to content, to the object being vehiculated, and this shift is extremely important if wanting to acquire professional content and know-how. This consideration calls to mind the requirements that CLIL students need to have, meaning that their language-competence level must be good enough to allow them to follow the CLIL lessons (Mearns, 2012). In such manner, the students' attention is focused more on the laboratorial aspect of the lesson shadowing the fact that instructions and comments on the experiments or activities carried out in class are in a foreign language, so that they, while doing, are learning, they are learning by doing. It is therefore fundamental for students to reach the level of language competence that Cummins (1999) calls Cognitive Academic Language Proficiency, the so-called CALP.

\subsection{Organizational and Methodological Problems for Teachers and Students within CLIL}

With the Gelmini Reform (2010), CLIL was institutionalized and therefore made curricular. Subject-matter teachers therefore are now required in person to teach their subject in a foreign language while in the past there had allegedly been closer cooperation between the subject-matter and language teachers just because of their specific competences.

In this perspective, the main problems that have now surfaced are mostly organizational and concern the difficulties in the cooperation and exchange among teachers. This raises the double-fold issue of, on the one hand, the subject-matter teacher not feeling up to the task of teaching his subject in the foreign language and, on the other, the language teacher being aware that he or she does not have the in-depth knowledge that the subject-matter requires.

The situation resulting from this lack of coordination in methodologic planning for CLIL shows how these strategies are self-standing and inappropriate to teach and evaluate both language and content.

Mehisto et al (2008) actually point out that the cooperation among teachers is an essential requirement to make a proper CLIL work. Keeping in mind all the problems considered 
above, the coordination among the teachers involved in a CLIL allows them to overcome many uncertainties by adopting specific methodologies: what needs to be limited to some minutes at a time is what is very typical of non-linguistic subjects which is the lecturing procedure, and therefore what shall be preferred is cooperative-learning; new strategies and techniques need to be introduced to develop an autonomous production in the foreign language, such as role-play or cloze and matching exercises; and in class what needs to be supplied to students are materials as authentic as possible. From a methodologic point of view, these shared teaching strategies determine better learning conditions since they allow to give input in a cyclical manner, meaning allowing to come back onto items, both linguistic and content-wise, by using different multisensorial channels and techniques in order to cater to different cognitive styles and learning strategies featured and adopted by students (Swain, 1985).

Following suggestions from the studies of Kong (2009) and Wyatt (2011), a set of solutions are here presented for the CLIL teacher beyond his or her own language and subject competences to be better prepared for a CLIL environment:

-acquire methodologic training specific for CLIL (Coyle et al., 2010; Ting, 2011);

-be flexible (Mehisto et al., 2008, 2012) and do team-work with subject and language teachers in order to plan the CLIL in all of its stages (De Santo \& De Meo, 2016);

-prepare the classwork so that the activities and exercises are effective, and leave room when planning for variables such as time, change of roles in who does what, or unforeseen outcomes of certain activities (Bosisio, 2015);

-find resources and materials both printed and electronic; and

-monitor and evaluate the process, the final product and the project itself (Morgan \& Carol, 2006; Serragiotto, 2007).

It must also be said that, although a subject teacher may have all the proper requirements to teach CLIL effectively, he or she may still need the support and expertise of a language teacher in the following moments:

-when planning: the subject teacher decides the subject-matter objectives, however the language teacher shall determine which language abilities to work on as he or she knows the linguistic level of each student in the class;

-when choosing materials: the subject teacher chooses the reference materials according to the objectives for content, however the language teacher is able to tell if certain texts are linguistically too difficult for the class and therefore recommend easier pieces of material or suggest to use in any case the originally selected materials and make them more understandable through specifically designed activities;

-when deciding the syllabus and which language contents to develop and how to do so: it is in fact recommendable before implementing a CLIL module that the main grammar structures, linguistic functions and vocabulary be covered by the language teacher during his or her 
lessons so that the student in the CLIL class is linguistically attuned and may keep his attention focused on the content of the lesson rather than needing to shift over to the language;

-when creating communicational moments in the foreign language (Rasulo et al., 2016);

-when designing activities that involve the students cognitively, calling upon their problem-solving skills (Willis, 1996); and

-when evaluating and correcting mistakes: the subject teacher oversees how exact, well-integrated and consistent the contents are, together with how effective the student is in communicating, while the language teacher corrects systematic language mistakes and can fill in possible language gaps (Zanoni, 2016).

The points here above dealt with represent instances and factors that cannot be overlooked when thinking about the effectiveness and operativity of CLIL. By concentrating on content and not on formal aspects of language, CLIL in fact creates the most favorable conditions for students to face a challenge cut out for their language skills and also their thinking and learning processes (Van de Craen, 2002).

\section{Conclusions}

Authors Di Martino and Di Sabato (2012) highlight the innovation that CLIL has brought to the Italian educational system in terms of improved language performance and better mastery of subject contents in a foreign language. The same authors, however, also point out that CLIL methodology requires a series of actions to be taken that need to be standardized, systematic and operational. The system, in fact, can easily turn into something problematic that compromises the integrity of the delicate process being unfolded.

These concerns are also shared by Pavón Vázquez and Rubio (2010) who believe it is recommendable to evaluate if, within a certain context, the competences available make the implementation of a CLIL worth the while, so that the project does not result being harmful for both the subject content and the foreign language being used.

This does not want to overshadow CLIL methodology; because of the belief in the worthiness of such methodology, it is recommended to carefully monitor its correct application and thoroughly examine all of its features. This means, in fact, reaffirming the importance of a methodological framework that integrates two very different disciplines and offers immediate and incisive solutions for a learning experience of superior quality.

As pointed out by the studies of Banegas (2012), today's CLIL teachers can avail themselves of several pedagogical and teaching models in order to create communicational situations that allow learners to reinforce their language and strengthen their mastery over content. CLIL teachers furthermore can take advantage of the many training opportunities offered at regional and national levels to fill in the gap between CLIL theory and its practical realization, producing the beneficial effects on learners mentioned above. This can happen only thanks to a vehicular methodology coming from careful planning and negotiation within the scholastic institution where teachers acknowledge the language and motivational levels of students and 
the expectations of their families. In such a context, it is possible to create a space for shared observations and evaluations on the pedagogical and educational implications of the CLIL experience in place, taking especially into account the difficulties, challenges and possible downfalls encountered in the process.

\section{References}

Ball, P., Kelly, K., \& Clegg, J. (2015). Putting CLIL into practice. Oxford: Oxford University Press.

Banegas, D. L. (2012). CLIL teacher development: Challenges and experiences. Latin American Journal of Content \& Language Integrated Learning, 5(1), 46-56. https://doi.org/10.5294/laclil.2012.5.1.4

Bosisio, N. (2015). CLIL in the Italian University, A Long but Promising Way to Go. EL.LE. 4(1), 133-154. https://doi.org/10.14277/2280-6792/2015/010/10

Bruton, A. (2011). Is CLIL so beneficial, or just selective? Re-evaluating some of the research. System, 39, 4, 523-532. https://doi.org/10.1016/j.system.2011.08.002

Cinganotto, L. (2016). CLIL in Italy: A general overview. Latin American Journal of Content and Language Integrated Learning, 9, 2, 374-400. https://doi.org/10.5294/laclil.2016.9.2.6

Coonan, C. M. (2005). The natural learning of a foreign language: CLIL as a possible partial solution for the primary school. Scuola e Lingue Moderne, 4, 5, 4-11.

Coonan, C. M. (2007). How are students engaged in subject learning through the LS? The case of secondary schools in Italy. In Dieter W., \& Marsh D. (ed.) Diverse Contexts, Converging Goals: Content and Language Integrated Learning in Europe (pp. 153-169). Mehrsprachigkeit in Schule und Untericht, 4, Frankfurt: Peter Lang.

Coonan, C. M. (2008). Insider views of the CLIL class through teacher self-observation-introspection. International Journal of Bilingual Education and Bilingualism, $10,5,625-646$.

Coonan, C. M. (2011). CLIL in (language) teacher training. Studi di Glottodidattica, 5, 2, 1-14.

Coonan, C. M. (2012). The foreign language curriculum and CLIL. Synergies Italie, 8, 117-128.

Coyle, D., Hood, P., \& Marsh, D. (2010). CLIL: Content and Language Integrated Learning. Cambridge: Cambridge University Press.

Cummins, J. (1999). BICS and CALP: Clarifying the Distinction. Retrieved August 25, 2017, from http://files.eric.ed.gov/fulltext/ED438551.pdf

Dalton-Puffer, C. (2011). Content-and-Language Integrated Learning: From Practise to Principles?. Annual Review of Applied Linguistics, 31, 182-204. https://doi.org/10.1017/S0267190511000092 
De Meo, A. (2015). From CLIL to ESP. The teacher's perspective. Napoli: Il Torcoliere.

De Santo, M., \& De Meo, A. (2016). E-training for the CLIL teacher: E-tutoring and cooperation in a Moodle-based community of learning. Journal of e-Learning and Knowledge Society, 12(3), 41-49.

Di Martino, E., \& Di Sabato, B. (2012). CLIL implementation in Italian schools: Can the long ago employed teacher be trained effectively? The Italian protagonists' voice. Latin American Journal of Content and Language Integrated Learning, 5(2), 73-105.

Escobar Urmeneta, C. (2010). Pre-service CLIL teacher-education in Catalonia. Expert and novice practitioners teaching and reflecting together. In Ruiz de Zarobe, Y., \& Lasagabaster, D. (eds.) CLIL in Spain: Implementation, results and teacher training (pp.188-218). Newcastle upon Tyne, UK: Cambridge Scholars.

European Commission (2008). Multilingualism: An asset for Europe and a shared commitment. Communication of the European Commission. Retrieved September 3, 2017, from http://eur-lex.europa.eu/legal-content/EN/TXT/?uri=celex:52008DC0566

Eurydice. (2012). Key data on teaching languages at school in Europe. Retrieved September 7, 2017, from http://eacea.ec.europa.eu/education/eurydice/documents/key_data_series/143EN.pdf

Graaff, R. D., Koopman, G. J., Anikina, Y., \& Westhoff, G. (2007). An Observation Tool for Effective L2 Pedagogy in Content and Language Integrated Learning (CLIL). International Journal of Bilingual Education and Bilingualism, 10(5), 603-624. https://doi.org/10.2167/beb462.0

Johnson, K., \& Swain, M. (1994). From Core to Content: Bridging the L2 Proficiency Gap in Late Immersion'. Language and Education, 8(4), 211-229.

Kong, S. (2009). Content-based instruction: What can we learn from content-trained teachers' and language-trained teachers' pedagogies?. Canadian Modern Language Review, 66(2), 233-267. https://doi.org/10.3138/cmlr.66.2.233b.

Lasagabaster, D., \& Sierra, J. M. (2009). Language attitudes in CLIL and traditional EFL Classes. International Journal of CLIL Research, 1(2), 4-17.

Li, D. C. S. (2002). Hong Kong parents’ preference for English-medium education: Passive victims of imperialism or active agents of pragmatism?. In Kirkpatrick, A. (Ed.). Englishes in Asia: Communication, identity, power, \& education (pp. 29-62).-Melbourne, Australia: Language Australia.

Lucietto, S. (2009). Tateo: A school and action research-based continuous professional development model for experienced/senior secondary teachers new to CLIL. In Marsh, D., Mehisto, P., Aliaga, R., Asikainen, T., Frigols, M., Hughes, S., \& Lange, G. (Eds.). CLIL practice: Perspectives from the field (pp. 117-124). Jyväskylä, Finland: University of Jyväskylä. 


\section{Macrothink}

International Journal of Linguistics ISSN 1948-5425 2017, Vol. 9, No. 5

Marsh, D., \& Wolf, D., (Ed.). (2007). Diverse Contexts, Converging Goals: Content and Language Integrated Learning in Europe. Frankfurt: Peter Lang.

Mearns, T. L. (2012). Using CLIL to enhance pupils' experience of learning and raise attainment in German and health education: a teacher research project. The Language Learning Journal, 40(2), 175-192. https://doi.org/10.1080/09571736.2011.621212

Mehisto, P., Marsh, D., \& Frigols, M. J. (2008). Uncovering CLIL: Content and Language Integrated Learning in Bilingual and Multilingual Education. Stuttgard: Macmillan Publishers Limited.

Morgan, C. (2006). Appropriate language assessment in content and language integrated learning. The Language Learning Journal, 33(1), 59-67.

O’Malley, J. M., \& Chamot, A. (1990). Learning strategies in Second Language Acquisition. Cambridge: Cambridge University Press.

Pavón Vázquez, V., \& Rubio, F. (2010). Teachers' concerns and uncertainties about the introduction of CLIL programmes. Porta Linguarum, 14, 45-58.

Rasulo, M., De Meo, A., \& De Santo, M. (2016). Processing Science through Content and Language Integrated Learning (CLIL). A Teacher's Practicum. In Oliveira, A., \& Weinburgh, M. (Ed.). Science Teacher Preparation in Content-Based Second Language Acquisition (pp. 305-322). Springer.

Ricci Garotti, F. (2007). Five methodological research questions for CLIL. In Marsh, D., \& Wolff, D. (Eds.). Diverse contexts-Converging goals: CLIL in Europe (pp. 131-144). Frankfurt: Peter Lang.

Serragiotto, G. (2007). Assessment and evaluation in CLIL', in Marsh, D., \& Wolff, D. (Eds.), Diverse contexts-Converging goals: CLIL in Europe (pp. 271-283). Frankfurt: Peter Lang.

Serragiotto, G. (2011). CLIL Methodology in Italy. In Bilingual Research. The Korean Society of Bilingualism, 45, 375-403.

Sisti, F. (2012). CLIL Experiences in Online Higher Education. In AA.VV., I Congreso Internacional de Enseñanza Bilingüe en Centros Educativos (pp. 1-17). Madrid: Universidad Rey Juan Carlos.

Swain, M. (1985). Communicative competence. Some roles of Comprehensible Input and Comprehensible Output in its Development. In Gases Madden, C. (Ed.), Input in second Language Acquisition (pp. 235-253). Rowley, MA: Newbury House.

Swain, M., \& Lapkin, S. (1982). Evaluating Bilingual Education: A Canadian Case Study. Ontario: Multilingual Matters.

Sylvén, L. K. (2013). CLIL in Sweden-why does it not work? A metaperspective on CLIL across contexts in Europe. International Journal of Bilingual Education and Bilingualism, 16(3), 301-320. https://doi.org/10.1080/13670050.2013.777387 


\section{Macrothink}

International Journal of Linguistics

ISSN 1948-5425

2017, Vol. 9, No. 5

Ting, Y. (2011). CLIL: not only not immersion but also more than the sum of its parts. English Language Teaching Journal, 65(3), 314-317.

Van de Craen, P. (2002). Content and Language Integrated Learning, Culture of Education and Learning Theories. In Bax, M., \& Jan-Wouter, Z. (Eds.). Reflections on Language and Language Learning (pp. 209-220). Amsterdam: John Benjamins Publishing.

Willis, J. (1996). A Framework for Task-Based Learning. Harlow, UK: Longman.

Wyatt, M. (2011). Teachers researching their own practice. ELT Journal, 65(4), 417-425. https://doi.org/10.1093/elt/ccq074

Zanoni, F. (2016). Code-switching in CLIL classes: A case study. EL.LE, 5, 2, 279-295. Retrieved July 28, 2017, from http://edizionicafoscari.unive.it/en/ edizioni/riviste/elle/2016/2/ code-switching-in-clil-classes-a-case-study

\section{Copyrights}

Copyright for this article is retained by the author(s), with first publication rights granted to the journal.

This is an open-access article distributed under the terms and conditions of the Creative Commons Attribution license (http://creativecommons.org/licenses/by/4.0/) 